\title{
Etnofísica, modelagem matemática, geometria... tudo no mesmo Manzuá
}

Ethnophysics, Mathematical Modeling, Geometry... All in the same Manzuá

\author{
Ednilson Sergio Ramalho de SOUZA ${ }^{1}$
}

\section{Resumo}

Meu objetivo neste artigo é apresentar os resultados parciais de uma pesquisa em desenvolvimento que visa analisar a Etnofísica dos ribeirinhos amazônicos com o intuito de desenvolver materiais didáticos inovadores para a abordagem de conceitos de Física e Matemática nas aulas do ensino médio e superior em ambiente de Modelagem Matemática. A questão de pesquisa foi: De que maneira a construção do Manzuá pode contextualizar aulas inovadoras de Física e Matemática no ensino médio? A metodologia usada foi abordagem etnográfica. Utilizei como fundamentos teóricos os referenciais da Etnomatemática (D'AMBRÓSIO, 2008), a Teoria dos Modelos Mentais (JONHSONLAIRD, 1983), Modelagem Matemática (CHAVES e ESPÍRITO SANTO, 2008) e a Teoria dos Campos Conceituais (VERGNAUD, 2007). Os dados iniciais sugerem que o conhecimento físico tradicional do sujeito pesquisado está fortemente relacionado a modelos mentais formados e reformulados em função dos longos anos de prática na construção do Manzuá e que os invariantes operatórios movimentados para construir o artefato fazem parte desses modelos mentais. As situações vivenciadas durante a construção do Manzuá podem embasar ótimas situações-problema para as aulas de Física e Matemática em ambiente de Modelagem Matemática. Podemos, portanto, a partir dessas situações, desenvolver materiais didáticos que relacionem o saber tradicional dos ribeirinhos ao saber da escola.

Palavras-chave: Etnofísica, Etnomatemática, Modelagem Matemática, Manzuá.

\begin{abstract}
The objective this is paper is to show partial results of research for project of doctorate whose intention is to analyze the Ethnophysics of the amazon fisherman end to develop innovative didactic resources for the conceptual approach in Physics and Mathematics in the classroom of the high school and higher education in environment of Mathematical Modeling. The research question was: How the build the Manzuá can contextualize lessons of Physics and Mathematics in high school?The methodology used was ethnographicresearch. The theoretical foundations were Ethnomathematics (D'AMBROSIO, 2008), Mental Models (JONHSON-LAIRD, 1983), Mathematical Modeling (CHAVES e ESPÍRITO SANTO, 2008) end Conceptual Field ((VERGNAUD, 2007). The initial results suggest which the traditional physical knowledge is strongly related to mental models formed in function long years practice in the construction of the Manzuá end the operational invariants take part in the mental models. The situations lived during the construction of the Manzuá can base situations-problem in the classes of Physics and Mathematics in environment of Mathematical Modeling. We can, therefore, develop didactics resources that relate the traditional knowledge to the school knowledge.
\end{abstract}

Keywords: Ethnophysics, Ethnomathematics, Mathematical Modeling, Manzuá.

\footnotetext{
${ }^{1}$ Universidade Federal do Oeste do Pará
} 


\section{Palavras iniciais}

- Seu Antônio, por que o senhor descasca essa madeira ainda verde para construir o Manzuá?

-É porque é mais fácil de dobrar e quando seca fica bem dura.

O diálogo acima se refere a um procedimento realizado durante a construção do Manzuá, um artefato construído por ribeirinhos para ser usado durante a pesca, e mostra que seu Antônio, um ribeirinho amazônico, movimenta conhecimentos físicos subjacentes sobre rigidez de materiais, densidade, força e troca de calor de forma espontânea. Seu Antônio, que nunca sentou no banco da escola, sabe que a madeira verde é mais flexível e, por isso, pode conformá-la mais facilmente. Sabe, também, que se colocar a madeira verde ao Sol ela vai secar e enrijecer. Esses conhecimentos foram conhecimentos adquiridos da própria prática de ribeirinho amazônico, ou seja, não foram conhecimentos repassados em bancos escolares. No entanto, o conhecimento físico tradicional de seu Antônio e o conhecimento formal escolar não são antagônicos. Eles podem ser complementares.

Meu objetivo neste artigo é apresentar os resultados parciais de uma pesquisa em desenvolvimento que visa analisar a Etnofísica dos ribeirinhos amazônicos e, a partir desse estudo, desenvolver materiais didáticos inovadores para a abordagem de conceitos de Física e Matemática em ambiente de Modelagem Matemática nas aulas do ensino médio e superior.

Sendo assim, o artigo segue buscando responder a seguinte questão: De que maneira a construção do Manzuá pode contextualizar aulas inovadoras de Física e Matemática no ensino médio? Para isso, uso como fundamentos teóricos os referenciais da Etnomatemática (D’AMBRÓSIO, 2008), a Teoria dos Modelos Mentais (JONHSON-LAIRD, 1983), da Modelagem Matemática (CHAVES e ESPÍRITO SANTO, 2008) e a Teoria dos Campos Conceituais (VERGNAUD, 2007).

Os resultados iniciais sugerem que o conhecimento físico tradicional de seu Antônio está fortemente relacionado a modelos mentais formados e refinados ao longo dos anos de prática na construção do Manzuá e que os conceitos-em-ação e teoremas-em-ação movimentados fazem parte desses modelos mentais.

Veremos que atitudes simples do professor como, por exemplo, investigar a construção e uso de artefatos tradicionais em sala de aula pode resultar em fonte de interesse e motivação por parte do alunado quando se relacionam os modelos mentais dos ribeirinhos aos modelos científicos da escola. Na próxima seção, farei um breve apanhado teórico sobre a Etnofísica. Seguirei com a apresentação da metodologia, resultados e discussões e findarei com as reflexões finais.

\footnotetext{
${ }^{2}$ Manzuá é um engradado de varas, empregado na pesca, espécie de covo, onde o peixe entra por uma abertura e não encontra a saída (http://www.dicio.com.br/manzua/).
} 


\section{Etnofísica}

De maneira geral, podemos entender Etnofísica como referência aos saberes populares acerca do conhecimento físico (PRUDENTE, 2010). A Etnofísica como campo de estudo emerge lentamente das pesquisas em Etnomatemática. É, portanto, um campo de estudo ainda novo na Ciência. Não vamos aqui definir Etnofísica, mas a definição dada por D’Ambrosio (2008) para o termo Etnomatemática poderia ser muito útil para entender o que seria Etnofísica. Assim diz o autor:

A definição de etnomatemática é muito difícil, por isso uso uma explicação de caráter etimológico. A palavra etnomatemática, como eu a concebo, é composta de três raízes: etno, e por etno entendo os diversos ambientes (o social, o cultural, a natureza, e todo mais); matema significando explicar, entender, ensinar, lidar com; tica, que lembra a palavra grega tecné, que se refere a artes, técnicas, maneiras. Portanto, sintetizando essas três raízes, temos etno+matema+tica, ou etnomatemática, que, portanto, significa o conjunto de artes, técnicas de explicar e de entender, de lidar com o ambiente social, cultural e natural, desenvolvido por distintos grupos culturais (D'AMBROSIO, 2008, p. 08).

Assim, em analogia à Etnomatemática, um olhar etnofísico significa considerar ontologicamente o modo de ver, de interpretar, de compreender, de explicar, de compartilhar, de trabalhar, de lidar, de sentir os fenômenos físicos. Em outras palavras o trabalho pedagógico com Etnofísica requer a apropriação da memória cultural do sujeito pesquisado, de seus códigos e símbolos, de seu universo microssocial.

As produções em Etnofísica, tanto em nível nacional quanto internacional, ainda são muito escassas. Não podemos, portanto, estabelecer uma categorização que leve a um "estado da arte" para Etnofísica. Ou seja, ainda não temos um referencial teórico consolidado para o assunto. No entanto, por serem pesquisas semelhantes, pelo menos metodologicamente, podemos emprestar alguns referenciais da Etnomatemática aos estudos de Etnofísica. Até agora, o que se pode considerar a respeito das poucas pesquisas que encontramos é que buscam motivar o aprendizado em Física quando tentam relacionar de alguma maneira o conhecimento tradicional em Física ao conhecimento escolar de sala de aula.

A dissertação de Anacleto (2007) teve o objetivo de investigar os conceitos físicos que os trabalhadores rurais pouco escolarizados do cultivo de arroz utilizam em suas práticas diárias e relacionar o conhecimento intuitivo de cada trabalhador com a parte formal que é trabalhada nas escolas e universidades. A pesquisa abrangeu a análise de procedimentos dos trabalhadores tais como a preparação do solo (nivelamento, construção de taipas, alisamento da terra, adubação), colheita, secagem e transporte do arroz. A partir de aplicação de questionários, observação participativa e entrevista a 14 trabalhadores do cultivo de arroz em uma Granja na cidade de Palmares do Sul-RS, a autora identificou que esses trabalhadores utilizam conceitos físicos e matemáticos durantes seus afazeres, mas não têm consciência dessa utilização.

Na prática, parecem usar e conhecer muitos princípios utilizados pela Física, para a explicação da realidade, mas não são conhecedores do jargão científico ou acadêmico próprio desta Ciência, ora por não ter tido suficiente tempo de escolarização, ora por não ter encontrado no ambiente escolar as ligações necessárias para que, tanto a Física quanto a 
Matemática, pudessem ser reveladas como parte integrante de suas vivências (ANACLETO, 2007, p. 80).

A pesquisa de Anacleto (2007) revelou que os trabalhadores do cultivo de arroz não encontram ligação entre os conhecimentos que utilizam com conceitos físicos e matemáticos que por acaso foram estudados na escola. Essa é uma constatação importante, pois o que se pretende com a Etnofísica é justamente estabelecer relação entre os conceitos empíricos utilizados por determinados grupos socioculturais aos conceitos ditos "formais" de sala de aula.

O artigo de Prudente (2010) analisou a possibilidade da Etnofísica como estratégia de ação pedagógica para o ensino de Física em turmas de Educação de Jovens e Adultos (EJA). O estudo foi feito em uma escola pública estadual na cidade de Goiânia-GO, com cerca de 80 estudantes. A autora enfocou a Etnofísica como uma maneira de trabalhar em sala de aula com a abordagem CTSA (Ciência, Tecnologia, Sociedade e Ambiente), no enlace dos saberes construídos pelo homem em seu ambiente cultural. Foi utilizado um grupo controle o qual não participou do projeto Etnofísica. A autora identificou que,

[...] os estudantes que participaram do Programa Etnofísica conceberam a Física como ciência da natureza, demonstrando uma compreensão da ideia basilar desta ciência. Ao passo que os educandos, que tiveram a mesma professora, mas passaram por um trabalho focado em fórmulas, acabaram por conceituar a Física sob essa mesma noção, que não vem a ser a essência dessa ciência natural, embora as fórmulas sejam importantes ferramentas (PRUDENTE, 2010, p. 08)

A importância dessa pesquisa reside em indicar que a partir da ação pedagógica numa perspectiva Etnofísica os estudantes tendem a ter outra concepção sobre a própria Física, que não aquela de uma ciência difícil e cheia de fórmulas.

O artigo de Barreto e Miltão (2011) teve o objetivo de investigar e fazer uma ligação entre os conhecimentos populares dos estudantes e professores das Escolas Famílias Agrícolas (EFAs) e o conhecimento científico em Física. Fizeram uma pesquisa exploratória para conhecer os educandos, professores e monitores da disciplina, saber os principais problemas que eles encontram para o ensino de Física, como os estudantes qualificam estudar Ciências em uma EFA, tentar identificar as áreas de trabalho que eles têm percepção no uso de conhecimentos físicos. A pesquisa se deu por meio de pesquisas de campo em quatro (04) EFAs, onde foram aplicados questionários, entrevistas e observações buscando compreender e respeitar a cultura do aluno. Por se tratar de uma pesquisa em sua fase exploratória, os autores apenas apontam como produto da mesma a fragilidade na organização curricular das referidas escolas quanto às competências da Física que devem ser privilegiadas, levando em conta os objetivos formativos desejados para essa comunidade cultural.

Além desses trabalhos, que abordam diretamente o tema Etnofísica, existem diversos outros na área de Etnomatemática que abordam indiretamente a Etnofísica. A tese de Lucena (2005), cuja pesquisa de campo investigou a construção artesanal de barcos e foi realizada no município de Abaetetuba-PA aborda, em caráter transdisciplinar, conteúdos de Matemática, Literatura e Artes, Geografia e História, Meio Ambiente, Saberes da Tradição e Física. A autora apresenta um quadro sinóptico que relaciona objetivos e conteúdos dessas áreas. Vejamos os objetivos e conteúdos de Física listados pela pesquisadora (LUCENA, 2005, p. 115): 
Objetivo1: Contextualizar o barco na vida do homem.

Conteúdos: Materiais que possuem a capacidade de flutuação e que foram usados pelo homem ao longo da história.

Objetivo 2: contextualizar o homem na vida do barco.

Conteúdos: Beneficiamento dos materiais flutuantes para a confecção de barcos; informações físico-experimentais sobre a flutuação dos barcos.

Objetivo3: Interagir com conhecimentos de base científica.

Conteúdos: Termos físicos envolvidos na mobilidade dos barcos: densidade e viscosidade.

Objetivo4: Interagir com conhecimentos de base nos saberes da tradição. Conteúdos: Informações sobre situações inusitadas sobre a construção dos barcos onde os mestres criam soluções próprias.

Objetivo5: contextualizar o barco na vida do homem.

Conteúdos: Materiais que possuem a capacidade de flutuação e que foram usados pelo homem ao longo da história.

Entendemos que a tese de Lucena (2005) é importante quando aborda, mesmo que indiretamente, diversas "Etnos", além da Etnomatemática tais como: "Etnoliteratura", "Etnoarte", "Etnohistória", "Etnogeografia" e, evidentemente, Etnofísica.

Os trabalhos comentados acima evidenciam que as pesquisas em Etnofísica são incipientes. É preciso adentrar mais profundamente nas investigações. Precisamos construir uma base teórico-epistemológica com referenciais da Educação Matemática e Científica específica para responder a determinadas questões sobre o assunto. Entendemos, portanto, que se necessitam de pesquisas com referenciais teóricos que envolvam representações mentais, campos conceituais, linguagens semióticas, situações didáticas as quais podem impulsionar as pesquisas em Etnofísica. $O$ trabalho de campo que apresento neste artigo segue uma agenda de pesquisas que procura usar de tais referenciais teóricos na interpretação dos resultados.

\section{Delineando a pesquisa de campo}

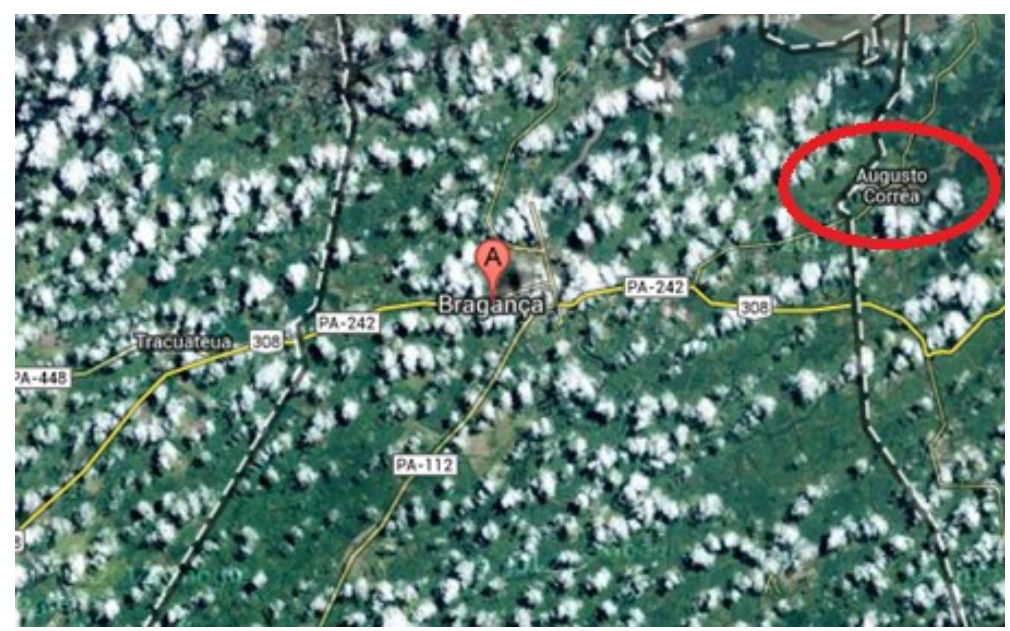

Figura 1. Augusto Correia, Bragança, Pa: lócus da pesquisa de campo (Fonte: https://maps.google.com.br/maps?hl=pt-BR\&tab=wl em 09 de junho de 2013).

A pesquisa de campo foi realizada no município de Augusto Correia (conhecido pela população local como Urumajó), próximo à cidade de Bragança, zona sudoeste do Estado 
do Pará, Brasil. Escolhi esse lócus em função da proximidade que tenho dos moradores ribeirinhos do local, pois, sempre que posso, fico alguns dias de férias nessa cidade.

No município de Augusto Correia, existem diversos grupos tradicionais, dentre os quais destaco: a comunidade de pequenos pescadores ribeirinhos, comunidade da produção de farinha de mandioca e macaxeira, os trabalhadores da Olaria (produção de tijolo \& telhas), os artesãos da cidade, o grupo da Marujada e os pequenos agricultores rurais. Minha pesquisa tem como população alvo os pescadores ribeirinhos da cidade. Escolhi os ribeirinhos por considerar que os sujeitos dessa população são os que normalmente mantêm residência distante do centro urbano e que, por consequência, são os que mais ficam alijados das políticas públicas. Neste trabalho, apresento os dados coletados quando acompanhava um dos ribeirinhos (seu Antônio) durante a construção de um artefato usado na pesca: o Manzuá.

Desta forma, considerando as especificidades procedimentais que a temática solicita busquei uma pesquisa de cunho qualitativo, a qual, segundo Marques et al. (2006),

\begin{abstract}
Buscar uma explicação da realidade via abordagem qualitativa corresponde compreendê-la a partir da revelação dos mapas mentais dos sujeitos-objeto da investigação. Interessa, pois, nessa abordagem apreender as percepções comuns e incomuns presentes na subjetividade das pessoas envolvidas na pesquisa, notadamente na condição de objetosujeito. Prestam-se como instrumentos de coleta de dados nessa abordagem a entrevista, questionários abertos, registros fotográficos, filmagens, técnica de discussão em grupo, observação sistemática e participante e outras que o investigador poderá criar e/ou adaptar (MARQUES et al., 2006, p. 38-39).
\end{abstract}

No âmbito da abordagem qualitativa, pretendi fazer uma pesquisa etnográfica que, segundo, Severino (2007),

visa compreender, na sua cotidianidade, os processos do dia-a-dia em suas diversas modalidades. Trata-se de um mergulho no microssocial, olhado com uma lente de aumento. Aplica métodos e técnicas compatíveis com a abordagem qualitativa. Utiliza-se do método etnográfico, descritivo por excelência (SEVERINO, 2007, p. 119) (Grifos do autor).

Sendo assim, para coletar os dados sobre os saberes tradicionais em Física durante a construção do Manzuá, acompanhei seu Antônio enquanto este fazia seus afazeres cotidianos, momentos em que fiz observações e entrevistas. Para facilitar o tratamento e interpretação dos dados, as entrevistas foram gravadas em vídeo e áudio, usando celular. Usei também um diário de bordo durante toda a pesquisa onde anotava pontos que julgava de interesse para atingir meus objetivos.

Para interpretar os dados obtidos, recorri principalmente às ideias presentes nas pesquisas em Etnomatemática (D'AMBROSIO, 2008), na Teoria dos Campos Conceituais de Vergnaud (2007), especialmente às ideias de invariantes operatórios (conceitos-em-ação e teorema-em-ação). O raciocínio de seu Antônio foi analisado, recorrendo principalmente à noção de Modelo Mental presente na Teoria dos Modelos Mentais de Jonhson-Laird (1983). Nossa concepção para o ambiente de Modelagem Matemática se aproxima da concepção de Chaves e Espírito Santo (2008). 


\section{Principais resultados}

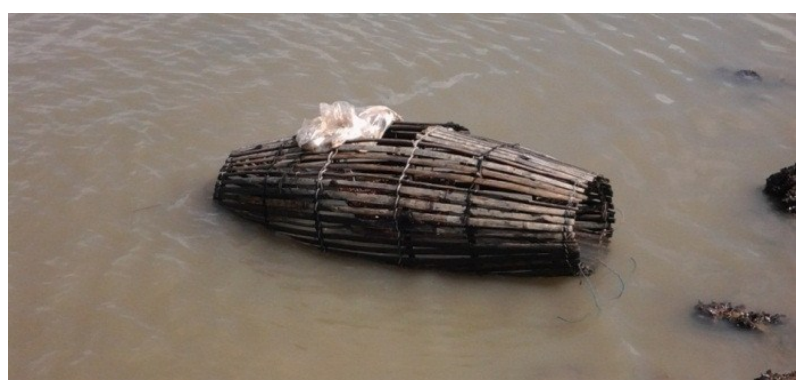

Figura 2. Manzuá ... Fonte: autor

O Manzuá é um artefato tradicional utilizado por populações ribeirinhas para a captura de peixes (Figura 2). Seu uso é feito em certas épocas do ano quando existe abundância de determinado peixe na região. O pescador coloca o Manzuá normalmente quando a maré está baixa, fixando-o pelas extremidades entre 04 pedaços de estacas. Durante a cheia do rio, o peixe é levado pela correnteza diretamente para a boca do artefato e fica preso dentro dele. Podemos entender a construção do Manzuá em dois momentos principais: a construção de seu "esqueleto" e o preenchimento do seu "esqueleto".

\section{O "esqueleto" do Manzuá}

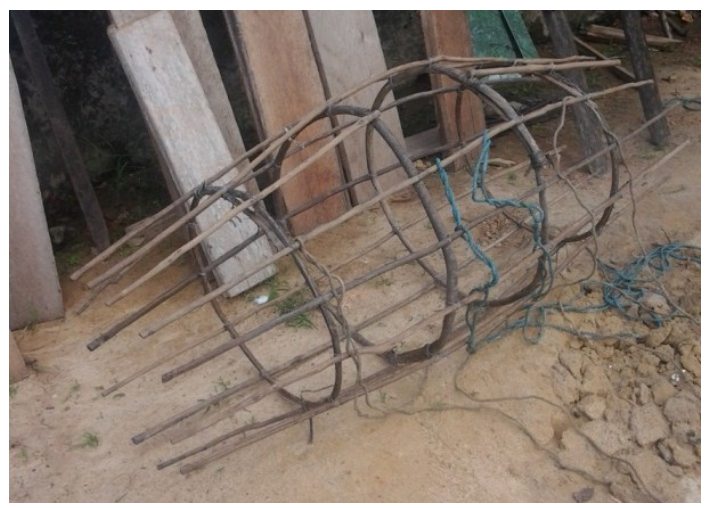

Figura 3. Manzuá em sua fase inicial de construção: o "esqueleto" do artefato.

O pescador inicia a construção do Manzuá, fazendo um "esqueleto" ou engradado de madeira. Para isso, usam-se tiras roliças dispostas paralelamente umas às outras espaçadas de aproximadamente $20 \mathrm{~cm}$ (01 palmo) as quais são amarradas em círculos de diferentes tamanhos feitos também de tiras roliças, sendo que os círculos maiores ficam no centro do "esqueleto" e os círculos menores ficam nas extremidades, dando uma ideia de tambor. (Figura 3).

Seu Antônio explica que o Manzuá deve ser feito com a madeira ainda verde. Isso possibilita que o pescador possa dar a forma circular mais facilmente ao objeto. As tiras de madeira verde são descascadas e amarradas em forma circular com linha de nylon. Depois de amarradas, são deixadas ao Sol. Quando a madeira seca, a circunferência fica com maior estabilidade, fazendo com que o esqueleto do artefato como um todo fique mais rígido. 


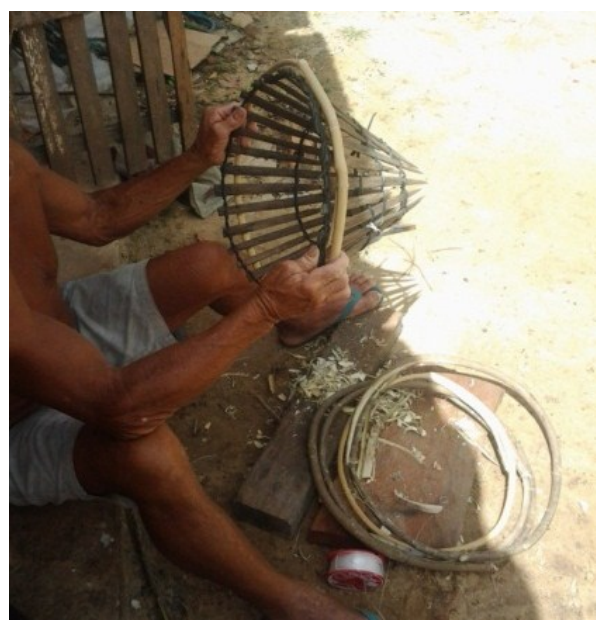

Figura 4. Seu Antônio dando forma circular às tiras de madeira verde.

Observa-se na figura 4 que seu Antônio descasca as tiras de madeira para que estas, depois de amarradas em forma circular e secas, ficam rígidas, ajudando na solidez do "esqueleto" do Manzuá.

\section{Preenchendo o "esqueleto" do Manzuá}

Depois que o "esqueleto" do Manzuá fica pronto, sua extensão lateral é totalmente preenchida com varas achatadas de madeira também verde. O resultado final pode ser visto na figura 2.

Seu Antônio explica que nessa parte do trabalho é importante que as tiras de forma mais achatadas não fiquem muito longe uma das outras e que também não fiquem muito unidas e que é preciso amarrá-las bem forte porque a força da água do rio pode soltar alguma ripa e o peixe fugir.

Explica o pescador, também, que depois de uma semana secando ao Sol, o Manzuá já pode ir para o rio. Ele comenta que devemos colocar o Manzuá quando a água do rio está baixa e também temos que saber por onde o peixe "gosta de nadar". Deve-se ter o cuidado para que uma das bocas do artefato fique na direção contrário da correnteza durante a cheia do rio. Depois que o peixe entra no Manzuá, ele não consegue mais sair devido as duas bocas do artefato possuírem pontas viradas para dentro (observar a figura 4). "Se o peixe tentar fugir, ele se espeta", comenta seu Antônio.

\section{Algumas discussões}

Acompanhando a construção do Manzuá, pude notar diversos momentos em que seu Antônio fazia uso de conceitos físicos, tais como: densidade, força, vazão, volume, calor, temperatura, flexão de hastes, rigidez de materiais.

Os modelos mentais utilizados por seu Antônio durante a construção do Manzuá parecem ser modelos refinados pela própria prática, pois ele faz o artefato antevendo os procedimentos antes mesmo de executá-los (simulação mental), podendo evitar erros que levariam ao maior tempo na construção do artefato. Isso fica evidente quando ele segue uma espécie de roteiro mental para construir o Manzuá (coletar madeira verde, descascar a madeira, fazer círculos de diferentes tamanhos, secar ao Sol etc.). Borges (1998) argumenta que os modelos mentais possibilitam simulação mental, 
Muito do nosso raciocínio consiste em imaginar como um dado estado de coisas desdobra-se em uma série de outros eventos, o que pode ser entendido em termos de nossos modelos mentais. Um modelo mental é conhecimento sobre uma determinada questão ou domínio que usamos para pensar sobre eles por meio de simulação mental. Tais modelos têm a característica de capacitar-nos a realizar ações inteiramente na imaginação. Isso permite-nos internalizar as representações que criamos para as coisas e estados de coisas no mundo e processá-los como se fossem externos (BORGES, 1998, p. 14).

O fato de seu Antônio possuir modelos mentais refinados e consolidados para a construção do Manzuá fica evidente também quando se observa que ele não comete equívocos durante a construção e utilização do artefato. Os modelos mentais possibilitam que seu Antônio inicie todo o processo sabendo exatamente o que deve fazer para resolver os problemas e onde vai chegar.

O modelo mental usado para a construção e utilização do Manzuá indica que os conhecimentos físicos que o pescador movimenta também estão representados como modelos mentais. Seu Antônio sabe exatamente a força que deve fazer na linha de nylon durante a amarração para deixar o Manzuá rígido de tal forma a não rompê-la, sabe perfeitamente quanto tempo deixar o Manzuá trocando calor ao Sol para que este não fique com rachaduras excessivas, sabe exatamente como fixar o Manzuá para que fique paralelo à velocidade do rio e evitar que a pressão da água o danifique. O conhecimento físico tradicional pertencente aos modelos mentais de seu Antônio pode ser avaliado a partir dos invariantes operatórios que são mobilizados. Moreira (1996) argumenta que os teoremas-em-ação e conceitos-em-ação são constituintes dos modelos mentais,

Pode-se, assim, dizer que os modelos mentais de Johnson-Laird contêm aquilo que Vergnaud chama de teoremas-em-ação, ou seja, proposições tidas como verdadeiras sobre o real. Mas esta aparente compatibilidade entre as duas teorias pode ir além, pois os conceitos-em-ação de Vergnaud também podem integrar modelos mentais. Conceitos-em-ação são objetos, predicados, ou categorias de pensamento, tidos como pertinentes, relevantes, à situação. Analogamente, segundo o princípio do construtivismo (Johnson-Laird, 1983, p. 398), um modelo mental é construído a partir de sinais ("tokens") dispostos em uma estrutura particular para representar em certo estado de coisas (isto é, uma certa situação). Se interpretássemos esses sinais ("tokens") como objetos, predicados ou categorias de pensamento pertinentes, dir-se-ia que os modelos mentais contêm também conceitos-em-ação (MOREIRA, 1996, p. 25).

Sendo assim, para analisar o conhecimento físico tradicional de seu Antônio durante a construção e utilização do Manzuá e comparar seus modelos mentais aos modelos científicos teríamos que nos focar nos invariantes operatórios que ele utiliza, os quais fazem parte dos tokens dos modelos mentais. Ou seja, a partir dos conhecimentos-em-ação (invariantes operatórios) de seu Antônio poderíamos relacionar seus conhecimentos físicos tradicionais aos conceitos formais da escola e propor o desenvolvimento de materiais didáticos inovadores. Nesse sentido, é interessante observar o que Vergnaud comenta sobre a experiência na formação dos invariantes operatórios,

No todos los invariantes operatórios vienen de los conceptos pragmáticos, ya que no todos son formulados y adoptados por La comunidad profesional que los utiliza. Pero todos se forman largamente em La 
experiencia, La cual aporta una contribución incontorneable al desarrollo. Esto no significa que La experiência sea em si misma suficiente: La formación continua contribuye también al desarrollo, particularmente al poner palabras a La experiencia, por la toma de conciencia metacognitiva, por los aportes de conocimientos nuevos; La formación inicial misma, aporta a los futuros profesionales categorías y operaciones de pensamiento, que lês permiten leer su experiencia de una manera más eficaz (VERGNAUD, 2007, p. 290).

Não vou adentrar nesta análise cognitiva por questão de espaço neste artigo e também por ser um assunto bastante complexo (deixarei para explorar esses enlaces conceituais em outro texto). Vou apenas apresentar algumas possibilidades que este estudo pode oferecer para o ensino de Física e Matemática.

Tomando por base as situações vivenciadas durante a construção e utilização do Manzuá, apresentarei no quadro 1, a seguir, algumas situações-problema que podem contextualizar a construção de recursos didáticos inovadores para o ensino de Física e Matemática. Na coluna da esquerda descrevo a situação-problema, na coluna do meio relaciono os conceitos físicos que eventualmente podem aparecer para resolver o problema e na coluna da direita apresento pelo menos um modelo matemático que pode ser (re) construído de forma contextualizada em sala de aula.

Quadro 1. Situações-problema, conceitos físicos e modelos matemáticos a partir da construção do Manzuá.

\begin{tabular}{|c|c|c|}
\hline Situação-problema & Conceitos físicos envolvidos & Modelos matemáticos \\
\hline $\begin{array}{l}\text { Em termos físicos por que seu } \\
\text { Antônio usa ripas roliças para } \\
\text { fazer o "esqueleto" do Manzuá } \\
\text { enquanto que nas paredes ele usa } \\
\text { ripas achatadas? }\end{array}$ & $\begin{array}{l}\text { Flexão de hastes, resistência de } \\
\text { materiais, pressão de líquidos. }\end{array}$ & $F=k y$ \\
\hline $\begin{array}{l}\text { Que conceitos físicos seu Antônio } \\
\text { utiliza quando usa madeira verde } \\
\text { descascada para fazer o Manzuá e } \\
\text { depois o coloca ao Sol para secar? }\end{array}$ & $\begin{array}{l}\text { Densidade, transferência de calor, } \\
\text { temperatura, energia cinética } \\
\text { molecular. }\end{array}$ & $\varnothing=\frac{Q}{\Delta t}$ \\
\hline $\begin{array}{l}\text { Fisicamente falando, por que seu } \\
\text { Antônio não deixa as tiras de } \\
\text { madeira achatadas que formam a } \\
\text { lateral do Manzuá muito unidas? }\end{array}$ & $\begin{array}{l}\text { Vazão, pressão de líquidos, } \\
\text { empuxo. }\end{array}$ & $p=\frac{F}{A}$ \\
\hline $\begin{array}{l}\text { Que aspectos físicos estão } \\
\text { envolvidos quando seu Antônio } \\
\text { coloca o Manzuá na direção } \\
\text { contrária à enchente do rio? }\end{array}$ & $\begin{array}{l}\text { Aceleração, velocidade, direção e } \\
\text { sentido, vazão. }\end{array}$ & $v=\alpha t$ \\
\hline
\end{tabular}

Usando como ambiente de aprendizagem a Modelagem Matemática, que concebemos em aproximação com a concepção de concepção de Chaves e Espírito Santo (2008), ou seja, 
Modelagem Matemática como um processo gerador de um ambiente de ensino e aprendizagem, no qual os conteúdos matemáticos podem ser conduzidos de forma articulada com outros conteúdos, de diferentes áreas do conhecimento, contribuindo dessa forma, para que se tenha uma visão holística (global) do problema em investigação (CHAVES e ESPÍRITO SANTO, 2008, p. 159).

Pensamos que diversos conceitos de Física e Matemática possam ser abordados (talvez de forma interdisciplinar), bem como vários modelos matemáticos possam ser (re) construídos juntamente com os alunos durante o estudo do Manzuá.

Por fim, poderíamos também utilizar a construção do Manzuá para contextualizar o estudo da Geometria Plana e Espacial em sala de aula de Ensino Médio, visando uma abordagem interdisciplinar Física e Matemática. O quadro 2, a seguir, relaciona as partes do Manzuá com algumas figuras planas e espaciais comumente estudadas nas aulas de Matemática do Ensino Básico.

Quadro 2. Elementos do Manzuá e conceitos matemáticos envolvidos.

\begin{tabular}{|c|c|}
\hline Elementos do Manzuá & Conceitos matemáticos envolvidos \\
\hline Aros circulares & Circunferência \\
\hline Boca do munzuá & Cone de cone \\
\hline
\end{tabular}

Destaca-se, ainda, que a Etnofísica pode enriquecer uma aula na abordagem Etnomatemática, na medida em que explora os conceitos físicos presentes na situação paralelamente aos conceitos matemáticos mobilizados. 


\section{Considerações finais}

Meu objetivo neste artigo foi analisar de que maneira a construção do Manzuá pode contextualizar aulas inovadoras de Física e Matemática no ensino básico. Para alcançar tal objetivo fiz uma pesquisa de campo do tipo abordagem qualitativa etnográfica, durante a qual acompanhei um ribeirinho (seu Antônio) na construção do artefato.

Verifiquei em diversos momentos que seu Antônio utilizava espontaneamente conhecimentos físicos tais como: força, pressão, rigidez de materiais, densidade, flexão de hastes, temperatura, transferência de calor. Percebi que esses conceitos não foram aprendidos na escola, uma vez que seu Antônio nunca tinha frequentado uma sala de aula. Então, concluí que tais conceitos tinham sido apreendidos durante a própria prática de construção do Manzuá.

Inferi que seu Antônio raciocinava com modelos mentais refinados pela prática à base de tentativas e erros. Esses modelos mentais possibilitavam a seu Antônio construir o artefato, seguindo um roteiro mental que possibilitava simulação mental. Ao antever os passos que seriam dados, seu Antônio eximia qualquer possível erro a ser cometido.

Baseado nas argumentações de Moreira (1996), refleti que os modelos mentais de seu Antônio contêm os invariantes operatórios (conceitos-em-ação e teoremas-em-ação). Analisando os invariantes operatórios de seu Antônio, poderíamos relacionar seus modelos mentais aos modelos científicos durante a construção do Manzuá e levar esse estudo para a sala de aula.

Propus também que as situações-problema vivenciadas durante a construção do artefato pudessem contextualizar aulas inovadoras de Física e Matemática em ambiente de Modelagem Matemática. No quadro 1, apresentei algumas situações, possíveis conceitos físicos a serem movimentados e modelos matemáticos a serem (re)construídos. Finalizei as discussões apresentando um quadro com conceitos de Geometria Plana a serem vistos de forma interdisciplinar durante a construção do Manzuá.

Sendo assim, buscando responder à minha questão norteadora, ou seja, de que maneira a construção do Manzuá pode contextualizar aulas inovadoras de Física e Matemática no ensino médio, reflito nas seguintes possibilidades:

Possibilidades Epistemológicas.

O Manzuá permite uma abordagem Etnofísica do conhecimento físico.

O Manzuá permite uma abordagem Etnomatemática do conhecimento matemático.

\section{Possibilidades Cognitivas.}

Podem-se estudar os modelos mentais dos ribeirinhos em função da prática tradicional na construção do Manzuá.

É possível avaliar os invariantes operatórios (conceitos e teoremas-em-ação) do ribeirinho durante a construção do Manzuá inter-relacionados aos conceitos da escola.

Possibilidade de favorecer a compreensão de conteúdos formais de Física quando se busca compreender os conhecimentos tradicionais movimentados na construção do Manzuá.

\section{Possibilidades metodológicas.}

Podem-se elaborar diversas situações-problema no contexto da construção do Manzuá como ponto de partida para a prática pedagógica em Física e Matemática. 
Pode-se usar a Modelagem Matemática como ambiente pedagógico em Física e Matemática.

As pontuações acima não compreendem a totalidade de possibilidades. A continuidade desta pesquisa consiste em desenvolver atividades pedagógicas a serem aplicadas e avaliadas em situação normal de ensino buscando outras possibilidades.

Sendo assim, nossa agenda de pesquisas segue buscando responder a outros questionamentos com relação à temática, tais como:

Como são os modelos mentais de conceitos físicos de determinado grupo tradicional?

Esses modelos mentais convergem ou divergem dos modelos científicos?

Quais as características dos conhecimentos-em-ação (conceitos-em-ação e teoremasem-ação) presentes no conhecimento físico dos sujeitos de um grupo cultural específico?

De que maneira os sujeitos de um grupo tradicional manipulam símbolos e códigos para externalizar seus conhecimentos a respeito de uma situação física?

As pesquisas em Etnofísica ainda têm muito a caminhar. Espero que esse artigo possa abrir discussões que valorizem e aproximem o saber tradicional dos ribeirinhos aos saberes necessários escola para a formação de cidadãos críticos e atuantes socioculturalmente, enriquecendo, assim, o ensino de Física e Matemática amazônico.

\section{Referências Bibliográficas}

ANACLETO, Bárbara da Silva. Etnofísica na lavoura de arroz. 2007. 101 p. Dissertação (Mestrado em Ensino de Ciências e Matemática). Universidade Luterana do Brasil. Canoas.

BARRETO, Ana Lucia Vilaronga; MILTÃO, Milton Souza Ribeiro (2011). A compreensão dos fenômenos físicos sob a perspectiva das famílias agrícolas. Disponível em http://www2.uefs.br/semic/upload/2011/2011XV-052ANA121-200.pdf. Acesso em: 02 jun. 2013.

BORGES, A. Tarcísio. Modelos mentais de eletromagnetismo. Caderno Catarinense de Ensino de Física. v. 15, n. 01, p. 07-31, abr. 1998.

CHAVES, Maria Isaura Albuquerque; ESPÍRITO SANTO, Adilson Oliveira. Modelagem matemática: uma concepção e várias possibilidades. Revista Bolema. Rio Claro, ano 21. n. 30, p. 149-161, 2008.

D'AMBROSIO, Ubiratan. O programa Etnomatemática: uma síntese. Revista Acta Scientiae, Canoas, v. 10, n. 01, p. 7-16, jan./jun. 2008.

JOHNSON-LAIRD, Philip Nicolas. Mental models: Towards a cognitive science of language, inference, and consciousness. 6 ed. Harvard: Harvard University Press, 1983.

LUCENA, Isabel Cristina Rodrigues de. Educação matemática, ciência e tradição: Tudo no mesmo barco. 2005. 209 p. Tese (Doutorado em Educação). Universidade Federal do Rio Grande do Norte. Natal.

MARQUES, Heitor Romero et al. Metodologia da pesquisa e do trabalho científico. 2 ed. Campo Grande: UCDB, 2006.

MOREIRA, Marco Antônio. A teoria dos campos conceituais de Vergnaud, o ensino de ciências e a pesquisa nesta área. Revista Investigações em Ensino de Ciências. v. 07, n. 01, p. 07-29, 2002.

PRUDENTE, Thaise Cristiane de Abreu. Etnofísica: uma estratégia de ação pedagógica possível para o ensino de física em turmas de EJA. Centro Científico Conhecer, Goiânia, v. 06, n. 10, p. 01-13, 2010.

SEVERINO, Antônio Joaquim. Metodologia do trabalho científico. 23 ed. São Paulo: Cortez, 2007. 
VERGNAUD, Gérard. ¿Enqué sentido la t eoría de los campos conceptualespuedeayudarnos para facilitar aprendizaje significativo? Revista Investigação em Ensino de Ciências. v. 12, n. 12, p. 285-302, 2007. 